\title{
VARIAÇÃO DA COMPOSIÇÃO QUÍMICA EM CULTIVARES DE BATATA DURANTE SEU DESENVOLVIMENTO (1)
}

\author{
DAYSE SOAVE SPOLADORE $\left({ }^{2}\right)$, JOÃO PAULO FEIJÃO TEIXEIRA $\left({ }^{2,4}\right)$, \\ MARCO ANTONIO TEIXEIRA ZULLO $\left({ }^{2,4}\right)$, SONIA MARIA BONILHA \\ MARCONDES COELHO $\left({ }^{3,4}\right)$ e HILÁRIO DA SILVA MIRANDA FILHO $\left({ }^{3,4}\right)$
}

\begin{abstract}
RESUMO
Estudou-se no presente trabalho a dinâmica de acúmulo de substâncias de reserva e glicoalcalóides totais, durante o desenvolvimento de tubérculos de três cultivares đe batata - Aracy (IAC-2), Itaiquara (IAC-3551) e Teberê (IAC-4489) - criados e selecionados pela Seção de Raízes e Tubérculos do Instituto Agronômico, no ano agrícola 1982/83, em plantio "das águas" (novembro-janeiro). Os resultados obtidos sấo referentes às amostragens realizadas aos 64,79 e 111 dias após o plantio (DAP), e mostraram que o cultivar Aracy acumulou maior quantidade de matéria seca, proteínas, cinzas, polissacarídeos totais e açúcares solúveis por tubérculo.
\end{abstract}

Termos de indexação: Solanum tuberosum L.; composição química; desenvolvimento de tubérculos.

\section{INTRODUÇÃO}

A batata (Solanum tuberosum L.) é uma planta predominante de clima temperado, mas a sua área de plantio em regiões tropicais e subtropi-

\footnotetext{
(1) Recebido para publicaçāo em 3 de maio de 1984.

$\left({ }^{2}\right)$ Seção de Fitoquímica, Insituto Agronốmico, (IAC), Caixa Postal 28, 13100 Campinas (SP).

(3) Seção de Raízes e Tubérculos, IAC.

$\left({ }^{4}\right)$ Com bolsa de pesquisa do CNPq.
} 
cais tem aumentado em função de sua alta capacidade de adaptação ao meio (PRODUCTION YEAR BOOK, 1971). Essa cultura constitui uma das mais importantes fontes de alimento, ao lado do arroz, trigo e milho. Seu tubérculo, além do consumo direto pelo homem, é utilizado pelas indústrias de alimento, álcool, amido e rações (MACEDO, 1976). Do ponto de vista nutricional, a batata apresenta características importantes, como proteínas de alto valor biológico e digestibilidade, fonte anti-escorbútica e ineficiente fonte de energia, já que o consumo diário de $200 \mathrm{~g}$ fornece apenas $5 \%$ da energia exigida por um homem de $70 \mathrm{~kg}$ (BURTON, 1974). Uma restrição ao consumo de tubérculo de batata é devida à presença.de substâncias tóxicas, representadas pelos glicoalcalóides esteroídicos, que ocorrem em maior concentração nas partes externas, periderme e córtex (HILTON, 1951; JADHAV \& SALUNKHE, 1975, e WOLF \& DUGGAR, 1946). Sendo estas características variáveis em nível de cultivar, é de interesse que os diferentes cultivares de batata, principalmente os nacionais, sejam avaliados para a determinaçâo desses parâmetros.

O objetivo deste estudo foi avaliar comparativamente a dinâmica de acúmulo de substâncias de reserva e glicoalcalóides totais durante o desenvolvimento de tubérculos de três cultivares de batata.

\section{MATERIAL E MÉTODOS}

O experimento foi realizado no ano agrícola $1982 / 83$, e o plantio, efetuado na época "das águas" (novembro-janeiro), no Centro Experimental de Campinas, Instituto Agronômico. Utilizou-se delineamento experimental de blocos ao acaso com três tratamentos e oito repetiçoes de campo, onde os canteiros apresentavam quatro linhas com $5 \mathrm{~m}$ de comprimento, espaçadas de $80 \mathrm{~cm}$. Na adubação, foi empregada a fórmula 4-14-8, na razão de $3 t /$ ha; trinta dias após o plantio, realizou-se cobertura com sulfato de amônio, $300 \mathrm{~kg} / \mathrm{ha}$.

Os cultivares estudados, Aracy (IAC-2), Itaiquara (IAC-3551) e Teberê (IAC-4489), foram criados e selecionados pela Seção de Raízes e Tubérculos, tendo seus tubérculos-semente sido produzidos na Estação Experimental de Itararé, do Instituto Agronômico.

As amostragens foram efetuadas aos 64, 79 e 111 dias após o plantio (DAP), sendo retirada do solo uma planta de cada repetição e levada ao laboratório, onde os tubérculos foram destacados da parte aérea, lavados, enxutos e pesados.

Em cada época, realizou-se a avaliação do teor de glicoalcalóides totais na porção superficial do tubérculo. Estas substâncias foram extraí- 
das de acordo com metodologia descrita por WANG et alii (1972) e analisadas como $\alpha$-solanina segundo SPOLADORE et alii (1983).

Também em cada época, os tubérculos foram colocados em estufa com circulação forçada de ar e mantida a uma temperatura de $60^{\circ} \mathrm{C}$, durante uma semana, até peso constante e pulverizados em moinho tipo "Willey". Os teores de polissacarídeos totais e açúcares solúveis foram determinados por colorimetria por meio da reação feno-ácido sulfúrico, segundo TEIXEIRA et alii (1979). O teor de cinzas foi avaliado de acordo com AOAC (1965), o de proteína bruta foi estimado através do teor de nitrogênio total após digestão da amostra, de acordo com técnica descrita por BATAGLIA et alii (1978). O extrato etéreo foi determinado por extração com hexano em extratores tipo "Soxhlet" por oito horas e avaliação gravimétrica segundo TRIEBOLD \& AURAND (1963).

\section{RESULTADOS E DISCUSSÃO}

As amostragens foram iniciadas aos 64 dias após o plantio (DAP), quando os cultivares estudados apresentaram tuberização suficiente para a realização das análises.

Pelo quadro 1, pode-se observar o número médio de tubérculos por planta, o peso médio de tubérculos, a produção média por planta e o teor de glicoalcalóides totais para cada cultivar nas diferentes épocas de amostragem.

\begin{tabular}{|c|c|c|c|c|}
\hline $\begin{array}{l}\text { Idade dos } \\
\text { tubérculios }\end{array}$ & $\begin{array}{l}\text { Número médio de } \\
\text { tuberculo/planta }\end{array}$ & $\begin{array}{l}\text { Peso médio do } \\
\text { tubérculo }\end{array}$ & $\begin{array}{l}\text { Produção média } \\
\text { por planta }\end{array}$ & $\begin{array}{c}\text { Glicoalcalöides } \\
\text { totais }\end{array}$ \\
\hline \multirow[t]{2}{*}{$\operatorname{DAP}\left({ }^{a}\right)$} & & $\mathbf{g}$ & 8 & $\mathrm{mg} / \operatorname{lo0g}\left({ }^{b}\right)$ \\
\hline & \multicolumn{3}{|c|}{ Oulrivar Aracy } & \\
\hline 64 & 10 & 17,81 & 178,10 & 7,26 \\
\hline 79 & 15 & 32,13 & 481,95 & 5,15 \\
\hline \multirow[t]{2}{*}{111} & 11 & 54,81 & 602,91 & 6,12 \\
\hline & \multicolumn{3}{|c|}{ Cultivar Itaiquara } & \\
\hline 64 & 9 & 20,63 & 185,67 & 8.98 \\
\hline 79 & 15 & 46,54 & 698,10 & 8,01 \\
\hline \multirow[t]{2}{*}{111} & 16 & 48,98 & 783,68 & 9,09 \\
\hline & \multicolumn{3}{|c|}{ Gultivat Teberë } & \\
\hline 64 & 12 & 19,91 & 238,92 & 9,09 \\
\hline 79 & 19 & 26,64 & 506,16 & 8,76 \\
\hline 111 & 19 & 37,44 & 711,36 & 9,98 \\
\hline
\end{tabular}

(a) DAP = dias após o plantio; (b) miligrama de glicoalcaloides $/ 100 \mathrm{~g}$ de porçăo superficial de tubérculo. 
O peso médio de matéria verde ganho nos intervalos de 64 a 79 DAP, e de 79 a 111 DAP para o 'Aracy' foi de 955 e de $709 \mathrm{mg} /$ dia/tubérculo respectivamente. Para matéria seca, nesse mesmo período, o peso médio ganho foi de 168 e $164 \mathrm{mg} / \mathrm{dia} /$ tubérculo. Para o 'Itaiquara', o peso médio de matéria verde ganho nos mesmos intervalos foi de 1.783 e de $76 \mathrm{mg} / \mathrm{dia} / \mathrm{tu}$ bérculo, e para matéria seca, de 276 e de $71 \mathrm{mg} /$ dia/tubérculo. O 'Teberê' apresentou um ganho de matéria verde de 449 e $338 \mathrm{mg} / \mathrm{dia} /$ tubérculo, enquanto para matéria seca foi de 115 e de $81 \mathrm{mg} /$ dia/tubérculo, nos mesmos intervalos de a mostragem.

O 'Aracy' apresentou teores de glicoalcalóides totais menores do que os dos cultivares Itaiquara e Teberê,independente da época de amostragem.

Na figura 1, são mostrados os valores médios, expressos em grama/ tubérculo, de matéria verde (M.V.), matéria seca (M.S.), polissacarídeos totais (P.T.), proteína bruta (P.B.), cinzas ( $\mathrm{Cn}$ ), açúcares solúveis (A.S.), extrato etéreo (E.E.) e glicoalcalóides totais (TGA), para cada cultivar, nas diferentes épocas de amostragem.
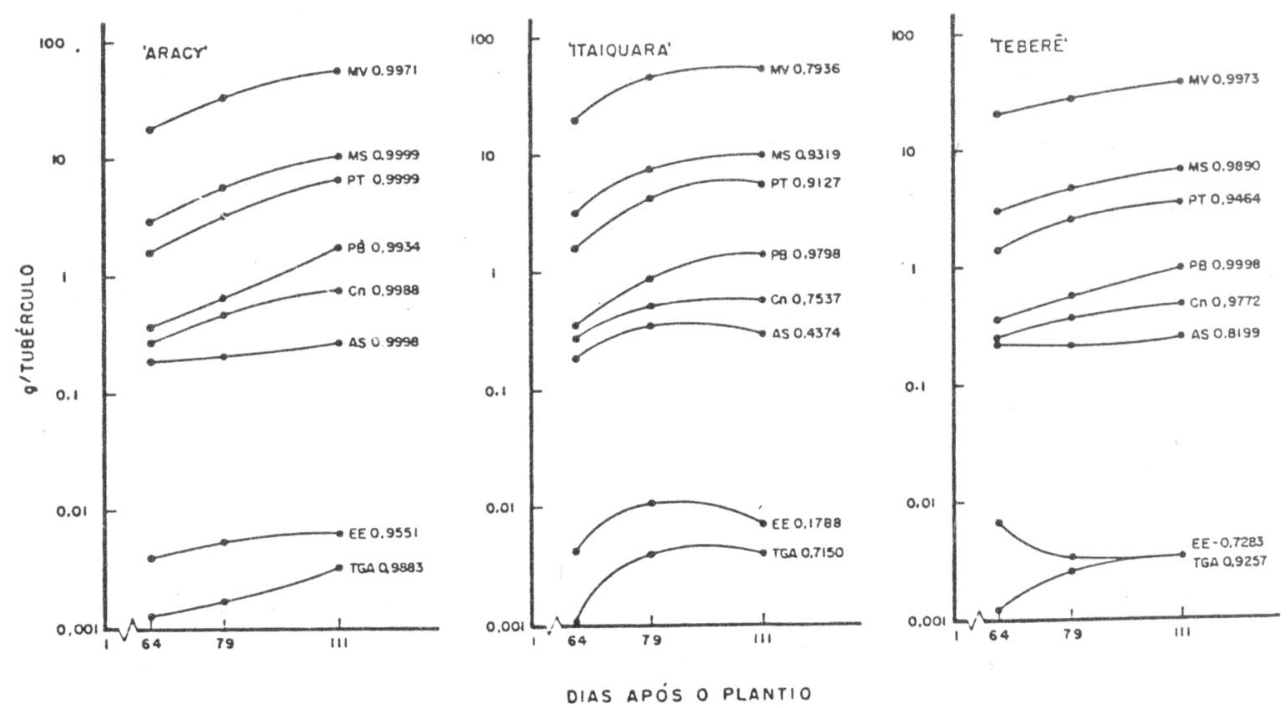

FIG!JRA 1 - Acúmulo de matéria verde (M.V.), matéria seca (M.S.), polissacarídeos totais (P.T.), proteína bruta (P.B.), cinzas (Cn), açúcares solúveis (A.S.), extrato etéreo (E.E.) e glicoalcalóides totais (TGA), por tubérculo, durante o desenvolvimento de tubérculos dos cultivares Aracy, Itaiquara e Teberê.

Os números à direita das curvas são os coeficientes de correlação do item em questão com a data de colheita. 
De modo geral, os valores destas determinações tendem a estabilizar-se aos 79 DAP para o 'Itaiquara', classificado como precoce de brotação e maturação, em torno de 111 DAP para o 'Teberê', meio tardio de brotação e maturação, ao passo que não se nota estabilização destes valores para o 'Aracy', tardio de brotação e maturação.

Os três cultivares apresentaram um comportamento bastante diferenciado quanto aos valores de extrato etéreo por tubérculo, no periodo de amostragem. Enquanto em 'Aracy' estas quantidades são sempre crescentes, em 'Teberê' se mostram sempre decrescentes, ao passo que em 'Itaiquara' atingem um máximo aos 79 DAP.

Os teores de glicoalcalóides totais em qualquer dos cultivares e em qualquer época de amostragem, não se mostraram correlacionados a nenhum dos teores de polissacarídeos totais, proteína bruta, cinzas, açúcares solúveis, extrato utéreo, bem como a matéria verde e matéria seca.

De modo geral, entretanto, há correlação entre os valores determinados por tubérculo e o periodo de colheita, para cada cultivar, conforme também mostrado na figura 1 , sendo tanto maiores os coeficientes de correlação quanto mais tardios os ciclos de brotação e maturação.

\section{SUMMARY}

VARIATION IN THE CHEMICAL COMPOSITION OF POTATO TUBERS OF THREE CULTIVARS DURING THE GROWING SEASON

In the rain season of 1982-1983 (November-January), it was studied the dynamics of accumulation of reserve substances and total glycoalkaloids in growing tubers of the Brazilian potato cultivars Aracy (IAC-2), I taiquara (IAC-3551) and Teberê (IAC-4489). Data are related to three sampling dates, 64, 79 and 111 days after planting (DAP). Tubers of Aracy (IAC-2) had the highest dry matter, protein, ash, total polisacharides and soluble e sugar contents.

Index terms: Solanum tuberosum L.; chemical composition; tuber growth.

\section{AGRADECIMENTOS}

Os autores agradecem ao Sr. Edgard Cesar Zerbinatti, técnico de laboratório da Seção de Fitoquímica, o auxílio prestado nas análises químicas, e à Sra. Rosemeire Araújo de Oliveira, os serviços de datilografia. 


\section{REFERÊNCIAS BIBLIOGRÁFICAS}

ANUÁRIO ESTATÍSTICO DO BRASIL. Rio de Janeiro, IBGE, v.39, 1978. ASSOCIATION OF OFFICIAL AGRICULTURAL CHEMISTS. Official methods of analysis. 10.ed. Washington, $1965.957 \mathrm{p}$.

BATAGLIA, O. C.; TEIXEIRA, J. P. F.; FURLANI, P. R.; FURLANI, A. C. M. \& GALLO, J.R. Métodos de análises químicas de plantas. Campinas, Instituto Agronômico, 1978. 31 p. (Circular, 87)

BURTON, W. G. Requirements of the users of ware potatoes. Potato Research, 17:374-409, 1974.

HILTON, R. J. Factors in relation to tuber quality in potatoes. Scientific Agriculture, $31: 61-70,1951$.

JADHAV, S. J. \& SALUNKHE, D. K. Formation and control of chlorophyll and glycoalkaloids in tubers of Solanum tuberosum and evaluation of glycoalkaloids toxicity. Advances in Food Research, 21:307-354, 1975.

MACEDO, M. C. M. Absorção de nutrientes por cultivares nacionais de batatinha (Solanum tuberosum L.). Piracicaba, ESALQ, 1976. 97p. Dissertação (Mestrado)

PRODUCTION YEARBOOK. Roma, FAO, v.25, 1971.

SPOLADORE, D. S.; ZULLO, M. A. T. \& TEIXEIRA, J. P. F. Extração e isolamento de $\alpha$-solanina de brotos de batata. Bragantia, Campinas, 42:255-259, 1983.

TEIXEIRA, J. P. F.; MASCARENHAS, H. A. A. \& BATAGLIA, D. C. Efeito de cultivares, tipos de solos e práticas culturais sobre a composição química de sementes de soja (Glycine max (L.) Merril). In: SEMINÁRIO NACIONAL DE PESQUISA DE SOJA, 1., Londrina, 1978. Anais. Londrina, EMBRAPA/CNPSo, 1979. v.1, p.11-16.

TRIEBOLD, H.O. and AURAND, L.N. Food composition and analysis. New York, van Nostrance, 1963.497p.

WANG, S. L.; BEFOR, C. L. \& THOMPSON, N. R. Determination of glycoat kaloids in potatoes ( $S$. tuberosum) with a bisolvent extraction method. American Potato Journal, 49:302-308, 1972.

WOLF, M.J. \& DUGGAR, B.M. Estimation and physiological role of solanine in the potato. Journal Agricultural Research, 73:1-32, 1946. 